\title{
POTRET PERILAKU KONSUMEN SAYURAN DI PERKOTAAN DAN PEDESAAN
}

\section{THE POTRAIT OF VEGETABLE CONSUMER'S BEHAVIOUR IN URBAN AND RURAL AREA}

\author{
Rosita Setiyawidi $^{1}$, Georgius Hartono ${ }^{2}$, dan Maria $^{2}$
}

Diterima 14 Desember 2012, disetujui 28 Juni 2013

\begin{abstract}
This research was aimed to know the importance order of vegetables attributes in urban and rural consumer; the relationship between external and internal factor and the quantity of factor that was considered in purchase of vegetables on urban and rural consumer; the difference of consideration on decision of purchasing vegetables between urban and rural area. The survey method was used in this research by collected questionnaire as much as 60 household. The location of this research at Kauman kidul and Salatiga Village, Salatiga City and November 15 to December 16, 2011. The data was analyzed conducted by Rank Spearman correlation and Mann Whitney nonparametric test. The result of this research indicated that :

1. In two area, the importance order of a vegetable attributes were benefit. And then followed by freshness, physical appearance, and price in urban area while in rural area followed by price, freshness, and physical appearance.

2. Both in urban and rural, external factor such as price, appearance and freshness of the vegetables significantly correlated with the quantity offactors that considered in the purchasing of vegetables.

3. In urban, variables in internal factor such as nutrition knowledge, family income, education and the number of family had significantly correlated with the quantity of factors that considered in the purchasing of vegetables. In rural, family income and education variables areas not significantly correlation with a quantity of factors that considered in the purchasing of vegetables but the variable of nutrition knowledge and the number of family members had significantly correlated.

4. From four consideration in buying decisions. The only significant difference was the kind of vegetables.
\end{abstract}

Keywords: considered in the purchasing, urban, rural, vegetables

\section{PENDAHULUAN}

Komoditas sayuran merupakan salah satu produk pertanian penting di Indonesia, hal ini dikarenakan komoditas tersebut memiliki potensi produksi yang tinggi (Abdul dan Indrie, 2009). Menurut Maria dan Melly (2007) sayuran adalah jenis pangan dalam empat sehat lima sempurna yang dibutuhkan tubuh untuk memenuhi kualitas konsumsi yang baik.
Dalam mengkonsumsi sayuran, setiap konsumen memiliki perilaku yang berbeda untuk membeli sayuran agar dapat memuaskan kebutuhan dan keinginannya. Pada proses pembelian sayuran tersebut, tentunya konsumen tidak asal-asalan dalam memilih, mempertimbangkan berbagai pilihan dan melakukan pembelian. Produk sayuran banyak tersedia di pasaran dan beragam jenisnya. Hal ini tentu membuat konsumen sayuran sangat selektif dalam melakukan pembelian.

\footnotetext{
${ }^{1}$ Alumni Fakultas Pertanian dan Bisnis, Universitas Kristen Satya Wacana

${ }^{2}$ Staff Pengajar Fakultas Pertanian dan Bisnis, Universitas Kristen Satya Wacana, email: g.hartono@ @staff.uksw.edu
} 
Perilaku konsumen dapat didefinisikan sebagai proses yang dilalui seseorang dalam mencari, mendapatkan dan mempergunakan barangbarang dan jasa termasuk di dalamnya proses pengambilan keputusan yang diharapkan dapat memenuhi kebutuhannya (Swastha dan Hani, 2000; Schiffman dan Kanuk, 2000). Proses tersebut merupakan sebuah pendekatan penyelesaian masalah pada kegiatan manusia untuk membeli suatu barang atau jasa dalam memenuhi kebutuhan dan keinginannya. Dalam hal ini ada banyak faktor yang mempengaruhi alasan konsumen membeli suatu produk tertentu dalam rangka memenuhi kebutuhan dan keinginannya. Simamora (2003) faktor-faktor yang mempengaruhi pengambilan keputusan pembelian seseorang dapat dibedakan menjadi faktor internal dan eksternal. Faktor internal berasal dari dalam diri individu konsumen sedangkan faktor eksternal berasal dari luar individu itu sendiri dalam mengambil keputusan pembelian sayuran. Faktor internal meliputi pendapatan keluarga, pemahaman gizi, jumlah anggota keluarga dan tingkat pendidikan. Faktor eksternal merupakan faktorfaktor diluar pribadi konsumen yang mempengaruhi pengambilan keputusan pembelian sayuran, terkait pada produk yang hendak dibeli meliputi: harga sayuran, tampilan fisik, dan kesegaran sayuran. Keputusan yang diambil oleh pembeli sebenarnya merupakan kumpulan dari sejumlah keputusan. Komponen pertimbangan pembelian sayuran antara lain waktu pembelian, tempat pembelian, jenis sayuran, dan jumlah pembelian yang diputuskan.

Dalam masyarakat modern, sering dibedakan antara masyarakat pedesaan (rural community) dan masyarakat perkotaan (urban community). Konsumen biasa memiliki kebiasaan dan tikah laku yang berbeda-beda, antara lain:

1. Lingkungan umum dan orientasi terhadap alam Masyarakat pedesaan berhubungan kuat dengan alam, karena lokasi geografisnya di daerah desa. Penduduk yang tinggal di desa akan banyak ditentukan oleh kepercayaan dan hukum alam. Berbeda dengan penduduk yang tinggal di kota yang kehidupannya "bebas" dari realitas alam.

2. Pekerjaan atau mata pencaharian

Pada umumnya mata pencaharian di daerah pedesaan adalah bertani tetapi ada juga yang bermata pencaharian berdagang, sebab beberapa daerah pertanian tidak lepas dari kegiatan usaha. Sedangkan di perkotaan relatif lebih heterogen.

\section{Diferensiasi sosial}

Keadaan heterogen dari penduduk kota berindikasi pentingnya derajat yg tinggi di $\mathrm{dlm}$ diferensiasi Sosial.

Berdasarkan uraian tersebut maka penulis ingin mengetahui potret atau gambaran perilaku konsumen sayuran di perkotaan dan pedesaan dalam keputusan pembelian sayuran yang dalam hal ini akan diketahui dari tujuan penelitian ini.

\section{METODE PENELITIAN}

Jenis penelitian yang dipakai ialah explanatory dengan menerapkan metode survai. Dilaksanakan pada bulan November-Desember 2011 dengan mengambil lokasi di dua tempat yaitu kelurahan Kauman Kidul dan kelurahan Salatiga, Kota Salatiga. Metode pengambilan sampel menggunakan purposive sampel, jenis judgement sampling yaitu sampel dipilih oleh peneliti berdasarkan pada tujuan penelitian (Kuncoro, 2003). Dalam penelitian ini, hanya rumah tangga yang membeli sayuran yang dapat dijadikan sampel. Dengan jumlah sampel 60 rumah tangga. Teknik pengumpulan data dilakukan melalui wawancara menggunakan kuisioner.

Dalam penelitian ini, untuk mencapai tujuan yang telah ditetapkan sebelumya digunakan beberapa alat analisis.Untuk mengetahui urutan kepentingan pada atribut sayuran dalam pengambilan keputusan pembelian sayuran menggunakan buku kerja Excel. Adapun cara untuk memperolehnya melalui nilai rata-rata dari masing-masing skor kepentingan atribut sayuran (manfaat, harga, tampilan fisik 
dan kesegaran). Tujuan kedua menggunakan analisis koefisien korelasi Rank Spearman. Kaidah keputusan dengan uji $t$ dua arah pada tingkat signifikansi 95 persen. Pada tujuan ketiga diuji dengan menggunakan uji Mann-Whitney. Kaidah keputusan yaitu jika nilai probabilitas $>0,05$ maka Ho ditolak artinya perilaku konsumen sayuran di pedesaan dan perkotaan berbeda secara signifikan. Jika nilai probabilitas $<0,05$ maka Ho diterima artinya perilaku konsumen sayuran di pedesaan dan perkotaan tidak berbeda secara signifikan.

\section{HASIL DAN PEMBAHASAN}

\section{Karakteristik Keluarga Sampel}

Sebanyak 50 persen sampel di perkotaan memiliki jumlah pendapatan keluarga di atas 2,5 juta sedangkan di pedesaan sepertiga dari sampel berpendapatan antara $1,5-2$ juta $(36,7 \%)$ dan $1-1,5$ juta (30\%). Jumlah anggota keluarga di perkotaan sebanyak 43,3 persen berjumlah kurang dari atau sama dengan 3 orang anggota dan di pedesaan sebanyak 40 persen sampel memiliki 4 orang anggota keluarga. Tingkat pendidikan dalam keluarga sampel di perkotaan yaitu sebanyak 43,3 pesen tamat SMA dan 36,7 persen berpendidikan sarjana. Sedangkan pada sampel di pedesaan sebanyak 73,3 persen tamat SMA dan tidak ada yang sarjana.

\section{Analisis sikap konsumen terhadap pembelian sayuran}

Sikap merupakan konsep paling penting dalam studi mengenai perilaku konsumen. Berbagai pertimbangan pembelian pada sayuran yang dievaluasi oleh konsumen meliputi harga, manfaat, tampilan fisik, dan kesegaran. Besaran skor untuk masing-masing variabel ditampilkan pada tabel 1 . Hasil penelitian menunjukkan variabel manfaat menjadi variabel yang dievaluasi terpenting oleh konsumen di perkotaan dan pedesaan dengan besaran skor 3,50 di perkotaan dan 3,43 di pedesaan.

Konsumen merasa variabel manfaat dinilai sangat penting dalam melakukan pembelian sayuran. Sayuran sangat diperlukan oleh tubuh karena merupakan sumber vitamin, mineral, dan serat yang diperlukan oleh manusia dalam menunjang kesehatan manusia. Hal ini sesuai dengan Kotler (1998), bahwa konsumen dalam melakukan pembelian adalah untuk mendapatkan manfaat dari produk yang dibelinya.

Bagi konsumen di perkotaan, setelah variabel manfaat selanjutnya variabel kesegaran dan tampilan fisik sayuran yang dinilai penting. Kesegaran sayuran dan tampilan fisik merupakan indikator kualitas sayuran yang masih layak untuk dikonsumsi sehingga kedua variabel ini dievaluasi penting dalam mempertimbangkan pembelian sayuran. Kesegaran dan tampilan fisik sayuran yang baik akan mendorong konsumsi sayuran konsumen perkotaan sehingga hal ini akan membuat konsumen lebih tertarik membeli. Selanjutnya harga sayuran merupakan variabel yang dievaluasi atau dipertimbangkan terakhir dalam pembelian sayuran. Konsumen di perkotaan sangat mementingkan mengenai manfaat, kese-

Tabel 1. Urutan kepentingan dalam pembelian sayuran pada konsumen di perkotaan dan pedesaan

\begin{tabular}{clclc}
\hline \multirow{2}{*}{ Peringkat } & \multicolumn{2}{c}{ Perkotaan } & \multicolumn{2}{c}{ Pedesaan } \\
\cline { 2 - 5 } & Variabel & Skala & Variabel & Skala \\
\hline 1 & Manfaat & 3,50 & Manfaat & 3,43 \\
2 & Kesegaran & 3,27 & Harga & 3,27 \\
3 & Tampilan & 2,97 & Kesegaran & 3,23 \\
4 & Harga & 2,47 & Tampilan & 3,07 \\
\hline
\end{tabular}

Sumber: Analisis Data Primer (2012) 
garan, dan tampilan fisik sayuran yang dikonsumsinya dalam mencukupi kebutuhan gizi seluruh anggota keluarga sehingga berapapun harga sayuran di pasaran akan tetap memutuskan membeli.

Di pedesaan konsumen mengevaluasi harga sayuran sebagai variabel penting kedua setelah manfaat. Jika harga sayuran naik, konsumen akan cenderung membatalkan pembelian dan lebih memilih sayuran dari kebun sendiri atau meminta kepada tetangga yang memiliki. Harga sayuran bagi konsumen di pedesaan akan sangat dipertimbangkan karena mempengaruhi besarnya jumlah pengeluaran keluarga untuk membelinya. Selanjutnya variabel kesegaran sayuran dan tampilan fisik sayuran menjadi urutan terakhir tingkat kepentingan. Keluarga di pedesaan mengolah sayuran menjadi makanan matang. Bagian sayuran yang kurang baik dibuang dan bagian yang kotor dibersihkan sehingga tampilan sayuran menjadi pertimbangan terakhir dalam melakukan pembelian sayuran.

\section{Hubungan faktor eksternal dengan keputus- an pembelian sayuran di perkotaan dan di pedesaan}

Faktor eksternal merupakan faktor diluar individu konsumen yang mempengaruhi keputusan pembelian. Dalam model Kotler dan Amstrong (2001) faktor eksternal disebut stimuli, yang terdiri dari stimuli pemasaran dan lingkungan makro. Penelitian ini hanya akan meneliti stimuli pemasaran antara lain: harga produk, tampilan fisik, dan kesegaran sayuran.
Hasil pengujian komputasi menunjukkan bahwa nilai t hitung untuk variabel harga, tampilan dan kesegaran di kedua daerah lebih besar dari t tabel artinya faktor eksternal berhubungan signifikan dengan jumlah faktor yang dipertimbangkan dalam pembelian sayuran pada konsumen di perkotaan dan pedesaan.

Variabel harga di dua daerah terbukti terdapat hubungan yang signifikan ( $\mathrm{t}$ hitung $>\mathrm{t}$ tabel). konsumen di perkotaan sangat mengutamakan kualitas sayuran yang dibelinya. Di pagi hari, biasanya harga sayuran masih tinggi, namun setelah menjelang siang, harga akan turun dikarenakan kualitas sayuran yang telah menurun yaitu tampilan fisik menjadi jelek dan sayuran kurang segar. Dalam keadaan yang demikian konsumen di perkotaan jika membeli sayuran dengan harga rendah akan banyak mempertimbangkan karena berasumsi bahwa kualitas sayuran tersebut buruk. Berbeda dengan konsumen di pedesaan di mana harga sangat dipertimbangkan dalam pembelian sehingga pada tingkat harga sayuran rendah konsumen sedikit mempertimbangkan. Dan jika harga naik atau tinggi akan banyak mempertimbangkan.

Selanjutnya untuk tampilan fisik sayuran diperoleh nilai thitung lebih besar dari t tabel untuk kedua daerah.Tampilan fisik sayuran yang baik meliputi kebersihan sayuran, kesempurnaan bentuk dan tidak berulat. Dalam melakukan pembelian, konsumen akan mempertimbangkan kualitas barang pilihannya apalagi sayuran yang akan dikonsumsi berkaitan dengan kesehatan keluarga. Tampilan fisik sayuran dapat digunakan untuk menilai kualitas sayuran. Konsumen di perkotaan

Tabel 2. Hasil pengujian komputasi hubungan faktor eksternal dengan keputusan pembelian sayuran

\begin{tabular}{|c|c|c|c|c|c|c|}
\hline \multirow[b]{2}{*}{ Variabel } & \multicolumn{3}{|c|}{ Perkotaan } & \multicolumn{3}{|c|}{ Pedesaan } \\
\hline & $\begin{array}{c}\text { Koef } \\
\text { Korelasi }\end{array}$ & Hubungan & $\begin{array}{l}\text { Nilai t } \\
\text { hitung }\end{array}$ & $\begin{array}{l}\text { Koef } \\
\text { Korelasi }\end{array}$ & Hubungan & $\begin{array}{l}\text { Nilai t } \\
\text { hitung }\end{array}$ \\
\hline Harga & $-0,21$ & Rendah & 3,27 & 0,15 & Sangat rendah & 8,76 \\
\hline Tampilan & 0,16 & Sangat rendah & 11,59 & 0,15 & Sangat rendah & 11,89 \\
\hline Kesegaran & 0,25 & Rendah & 20,53 & 0,20 & Rendah & 18,15 \\
\hline
\end{tabular}

Keterangan : Selang Kepercayaan $=95 \%, 2$ sisi, $\mathrm{n}=30, \mathrm{t}_{(0,025)}=2,045$

Sumber : Analisis Data Primer, 2012 
memilih sayuran yang benar-benar baik tampilan fisiknya, tetapi pada beberapa konsumen dapat mentolerir adanya ulat di sayuran karena menurutnya sayuran lebih aman dari pestisida sehingga lebih sehat dikonsumsi. Di pedesaan konsumen dapat menerima sayuran yang mungkin kurang baik keadaannya. Konsumen beralasan jika sayuran kotor dapat dibersihkan dan bagian yang jelek dapat dibuang. Tetapi jika sayuran benarbenar jelek tampilan fisiknya konsumen akan membatalkan pembelian.

Bagi konsumen sayuran di kedua daerah, kesegaran sayuran sangat penting dalam pertimbangan pembelian sayuran. Terbukti dengan nilai thitung $>\mathrm{t}$ tabel (lihat tabel 2). Kesegaran sayuran berkaitan dengan manfaat yang akan diperoleh. Konsumsi sayuran banyak membawa dampak yang baik bagi kesehatan tubuh. Namun, jika sayuran tersebut telah layu dan keriput kenampakkannya maka sayuran sudah tidak bermanfaat lagi karena vitamin, mineral dan serat dalam sayuran telah hilang. Selain itu, sayuran yang telah layu akan menyebabkan masakan tidak enak dimakan sehingga konsumen hanya akan membeli sayuran dengan kesegaran sayuran yang tinggi.

\section{Hubungan faktor internal dengan keputusan pembelian sayuran di perkotaan dan di pedesaan}

Faktor internal adalah faktor yang berasal dari dalam diri seseorang yang seringkali tidak disadari oleh konsumen (Simamora, 2003). Dalam penelitian ini ada empat variabel yang diteliti hubungannya dengan pertimbangan keputusan pembelian sayuran antara lain: pemahaman gizi, pendapatan, jumlah anggota keluarga, dan pendidikan.
Dengan melihat tabel 3 hasil pengujian komputasi hubungan faktor internal dengan keputusan pembelian sayuran, diketahui bahwa pada variabel pemahaman gizi terdapat hubungan yang signifikan dengan jumlah faktor yang dipertimbangkan dalam pembelian sayuran untuk konsumen di perkotaan maupun di pedesaan. Nilai koefisien korelasi rank Spearman variabel pemahaman gizi di perkotaan menunjukkan hubungan yang sangat rendah dan negatif dengan nilai sebesar $-0,16$. Hal ini berarti konsumen dengan pemahaman gizi tinggi mempertimbangkan jumlah faktor dalam pembelian lebih sedikit dibandingkan dengan konsumen yang berpemahaman gizi sedang sampai rendah. Di pedesaan nilai koefisien korelasi variabel pemahaman gizi terhadap keputusan pembelian sayuran sebesar 0,46 yang berarti memiliki hubungan yang cukup dan positif yang artinya pada konsumen di pedesaan dengan pemahaman gizi yang tinggi mempertimbangkan jumlah faktor dalam pembelian lebih banyak dibandingkan konsumen dengan pemahaman gizi yang rendah.

Adanya hubungan yang signifikan antara pemahaman gizi dengan keputusan pembelian sesuai dengan dugaan semula. Pemamahan gizi seseorang akan menentukan kualitas makanan yang dikonsumsi sehingga seseorang yang memiliki pemahaman gizi yang baik akan lebih memahami untuk memilih dan mengkonsumsi sayuran yang berkualitas untuk keluarganya (Maria dan Melly, 2007).

$\underline{\text { Tabel 3. Hasil pengujian komputasi hubungan faktor internal dengan keputusan pembelian sayuran }}$

\begin{tabular}{|c|c|c|c|c|c|c|}
\hline \multirow[b]{2}{*}{ Variabel } & \multicolumn{3}{|c|}{ Perkotaan } & \multicolumn{3}{|c|}{ Pedesaan } \\
\hline & $\begin{array}{c}\text { Koef } \\
\text { Korelasi }\end{array}$ & Hubungan & $\begin{array}{l}\text { Nilai t } \\
\text { hitung }\end{array}$ & $\begin{array}{c}\text { Koef } \\
\text { Korelasi }\end{array}$ & Hubungan & $\begin{array}{l}\text { Nilai t } \\
\text { hitung }\end{array}$ \\
\hline Pemahaman gizi & $-0,16$ & Sangat rendah & 19,10 & 0,46 & Cukup & 28,34 \\
\hline Pendapatan & 0,16 & Sangat rendah & 5,77 & 0,09 & Sangat rendah & $-0,28$ \\
\hline Jmlh ang.klrg & $-0,13$ & Sangat rendah & 4,19 & 0,42 & Cukup & 7,64 \\
\hline Pendidikan & $-0,10$ & Sangat rendah & 4,55 & 0,22 & Rendah & $-0,57$ \\
\hline
\end{tabular}

Keterangan: Selang Kepercayaan $=95 \%, 2$ sisi, $\mathrm{n}=30, \mathrm{t}_{(0,025)}=2,045$

Sumber: Analisis Data Primer, 2012 
Sebagian besar konsumen di perkotaan mengetahui kandungan vitamin dan manfaatnya pada sayuran yang dibelinya. Dasar pengetahuan tersebut diperoleh dari majalah, televisi dan pengetahuan dari sekolah. Di pedesaan banyak dari konsumen yang tidak mengetahui kandungan vitamin dalam sayuran yang dibelinya namun demikian mengetahui manfaatnya. Pengetahuan ini diperoleh dari orang tua dan orang di sekitar tempat tinggalnya. Dengan pengetahuan gizi yang dimiliki maka orang yang bertugas untuk memutuskan pembelian sayuran (decider) memperhatikan kesehatan keluarganya. Selain itu, motif dalam pembelian sayuran tidak hanya karena selera keluarga tetapi juga manfaat dan dampaknya bagi kesehatan seluruh anggota keluarga.

Selanjutnya pada variabel pendapatan untuk konsumen di perkotaan terdapat hubungan yang signifikan antara pendapatan konsumen di perkotaan dengan jumlah faktor yang dipertimbangkan dalam pembelian sayuran. Namun, untuk konsumen di pedesaan nilai thitung lebih kecil dari $t$ tabel $(2,04)$ yang artinya tidak terdapat hubungan yang signifikan antara pendapatan konsumen di pedesaan dengan jumlah faktor yang dipertimbangkan dalam pembelian sayuran. Hasil analisis korelasi rank Spearman di perkotaan menunjukkan hubungan sangat rendah dengan nilai koefisien korelasi sebesar 0,16 . Tanda positif artinya konsumen yang berpendapatan tinggi mempertimbangkan jumlah faktor yang dipertimbangkan lebih banyak dibandingkan konsumen yang berpenghasilan kecil dan sebaliknya.

Pada konsumen di perkotaan terdapat hubungan yang signifikan antara variabel pendapatan dengan keputusan pembelian. Hal ini dikarenakan di perkotaan untuk mendapatkan sayuran haruslah membeli sehingga konsumen akan mempertimbangkan pendapatan keluarganya. Jumlah pendapatan keluarga akan menentukan alokasi dana yang digunakan untuk membeli sayuran maka jumlah pendapatan keluarga juga akan menen- tukan daya beli keluarga tersebut. Berbeda dengan di pedesaan di mana tidak terdapat hubungan yang signifikan antara variabel pendapatan dengan keputusan pembelian. Di pedesaan untuk mendapatkan sayuran tidak harus membeli tetapi bisa mengambil sayuran yang ada dari lingkungan sekitar tempat tinggalnya.

Selanjutnya pada variabel jumlah anggota keluarga di kedua daerah penelitian menunjukkan terdapat hubungan yang signifikan antara variabel jumlah anggota keluarga dengan jumlah faktor yang dipertimbangkan dalam pembelian yang dibuktikan dengan nilai t hitung yang lebih besar dari t tabel $(2,04)$. Nilai koefisien korelasi sebesar $-0,13$ di perkotaan berarti terdapat hubungan rendah dan negatif. Hal ini artinya konsumen dengan jumlah anggota keluarga kecil mempertimbangkan jumlah faktor pertimbangan pembelian banyak dibandingkan dengan konsumen yang memiliki jumlah anggota keluarga besar dan sebaliknya. Di pedesaan nilai koefisien korelasi sebesar 0,42 yang berarti terdapat hubungan yang cukup dan positif artinya di pedesaan konsumen yang memiliki jumlah anggota keluarga kecil mempertimbangkan jumlah faktor yang sedikit dibandingkan keluarga yang memiliki jumlah anggota besar akan mempertimbangkan banyak.

Hasil pengujian komputasi menunjukkan hubungan yang signifikan sesuai dengan dugaan semula bahwa jumlah anggota keluarga merupakan salah satu faktor yang mempengaruhi proses keputusan pembelian. Jumlah anggota keluarga akan menentukan jumlah yang akan dibeli. Menurut Hatane, Anette, dan Hellen (2007) keluarga memberikan pengaruh besar dalam perilaku pembelian seseorang. Menurut Simamora (2004) anggota keluarga pembeli dapat memberikan pengaruh yang kuat terhadap perilaku pembelian apalagi pada keluarga prokreasi yaitu keluarga yang terdiri atas suami-istri dan anak pengaruh pembelian akan sangat terasa. Keluarga kecil di perkotaan biasanya merupakan keluarga baru 
yang terdiri dari anggota keluarga inti yaitu ayah, ibu dan anak sedangkan di pedesaan keluarga berjumlah anggota kecil adalah keluarga yang hanya terdiri dari suami dan istri sedangkan anakanak mereka ada yang bekerja di luar kota atau telah menikah sehingga pergi meninggalkan rumah. Keadaan yang demikian berdampak dalam pertimbangan keputusan pembelian sayuran. Dengan jumlah anggota keluarga kecil di perkotaan decider dalam keluarga untuk pembelian sayuran akan lebih memiliki banyak pertimbangan karena dapat memperhatikan kebutuhan dan keinginan anggota keluarga lain jika jumlah anggota keluarga banyak maka decider dalam keluarga untuk pembelian sayuran menjadi kurang memperhatikan kebutuhan dan keinginan anggota keluarga keseluruhan sehingga jumlah keputusan yang dipertimbangkan sedikit.

Pada variabel pendidikan untuk konsumen di perkotaan berhubungan signifikan dengan jumlah faktor yang dipertimbangkan dalam pembelian sayuran (t hitung $>t$ tabel) sedangkan di pedesaan tidak berhubungan signifikan dengan jumlah faktor yang dipertimbangkan dalam pembelian sayuran ( $\mathrm{t}$ hitung $<\mathrm{t}$ tabel). Di perkotaan, nilai koefisien korelasi diperoleh nilai $-0,10$ yang menunjukan hubungan yang sangat rendah dan negatif artinya konsumen yang berpendidikan tinggi, jumlah faktor yang dipertimbangkan dalam pembelian sedikit dibandingkan dengan konsumen yang berpendidikan rendah.

Menurut Maria dan Melly (2007) latar belakang pendidikan formal erat hubungannya dengan kemampuan menyerap informasi dari berbagai sumber baik itu media elektronik maupun media masa. Adanya hubungan yang signifikan di perkotaan disebabkan karena konsumen di perkotaan merupakan masyarakat yang berpendidikan sehingga akan mempengaruhi pilihan pembeliannya. Oleh karena itu, dalam proses pembelian sayuran konsumen perkotaan mendasarkan pilihannya berdasarkan informasi dan pengetahuannya dari pendidikannya. Lain halnya di pedesaan pendidikan tidak berhubungan signifikan dengan keputusan pembelian dikarenakan konsumen sayuran di pedesaan yang tidak tinggi pendidikan formalnya mendapatkan pengetahuan mengenai manfaat sayuran dari orang tua dan orang sekitar tempat tinggalnya.

\section{Perbedaan keputusan pembelian sayuran antara konsumen di pedesaan dan perkotaan}

Dari hasil uji beda rata-rata menggunakan analisis non parametrik Mann-Whitney diperoleh nilai asymp. Sig untuk keputusan pembelian yaitu 0,40 $>0,05$ yang berarti tidak terdapat perbedaan keputusan pembelian antara konsumen di perkotaan dan di pedesaan. Hal ini berarti perilaku konsumen dalam pembelian sayuran di perkotaan dan di pedesaan pada Kota Salatiga relatif sama. Dalam pembelian sayuran melibatkan komponen pertimbangan yang disertakan yaitu antara lain tempat, waktu, jenis dan jumlah sayuran yang dibeli. Nilai asymp. Sig untuk tempat pembelian yaitu 0,11>0,05 artinya konsumen pada dua daerah tidak berbeda secara signifikan dalam mempertimbangkan tempat pembelian. Menurut hasil wawancara, konsumen mengaku mengkonsumsi sayuran telah menjadi kebiasaan sehingga sayuran menjadi makanan wajib yang harus ada di menu masakan sehari-hari. Dalam mendapatkan sayuran sehari-harinya konsumen di dua daerah penelitian tidak merasakan kesulitan atau hambatan apapun dan cenderung membeli sayuran di tempat yang dekat dengan tempat tinggalnya.

Nilai asymp. Sig untuk waktu pembelian yaitu 0,43 > 0,05 maka perilaku konsumen antara konsumen di perkotaan dan di pedesaan tidak ada perbedaan yang signifikan dalam mempertimbangkan waktu pembelian. Berdasarkan hasil wawancara dengan konsumen, waktu pembelian sayuran yang baik yaitu di pagi hari. Konsumen berpendapat pagi hari merupakan saat yang tepat untuk membeli sayuran karena sayuran masih tersedia dalam keadaan yang masih segar, tampilan fisik baik, dan tersedia beragam jenisnya. 
Untuk jenis sayuran angka asymp.Sig $0,04<0,05$ menunjukkan bahwa perilaku konsumen di perkotaan dan di pedesaan terdapat perbedaan yang signifikan dalam mempertimbangkan jenis sayuran. Untuk konsumen di perkotaan memilih jenis sayuran yang selain untuk diolah menjadi masakan juga cocok dan enak untuk dijadikan minuman (juice). Namun, di pedesaan pemilihan jenis sayuran yang dibeli hanya berdasarkan selera untuk diolah menjadi masakan menu sehari-hari keluarga.

Pertimbangan mengenai jumlah pembelian sayuran diperoleh nilai asymp. Sig 0,45>0,05 yang berarti bahwa perilaku konsumen di perkotaan dan di pedesaan tidak berbeda secara signifikan dalam mempertimbangkan jumlah pembelian sayuran. Sayuran memiliki sifat yang mudah rusak (perishable) dan waktu kesegaran yang tidak tahan lama sehingga sayuran tidak bisa disimpan dalam jangka waktu yang lama. Dalam pembelian, konsumen akan mempertimbangkan jumlah pembelian sesuai dengan kebutuhan keluarga.

\section{KESIMPULAN}

Dari hasil penelitian perilaku konsumen sayuran di perkotaan dan di pedesaan dapat ditarik kesimpulan sebagai berikut:

1. Urutan kepentingan atribut sayuran pada konsumen di perkotaan dan di pedesaan yang utama adalah manfaat. Atribut harga memiliki posisi yang terbalik antara perilaku konsumen perkotaan dan pedesaan. Oleh karenanya, perubahan harga pada tingkat konsumen pedesaan harus "diperhatikan".

2. Di perkotaan dan di pedesaan, faktor eksternal yaitu harga, tampilan fisik dan kesegaran sayuran berhubungan signifikan dengan jumlah faktor yang dipertimbangkan dalam pembelian sayuran.

3. Di perkotaan variabel-variabel dalam faktor internal berhubungan signifikan dengan jumlah faktor yang dipertimbangkan dalam pembelian sayuran. Di pedesaan, variabel pendapatan dan pendidikan tidak berhubungan signifikan dengan jumlah faktor yang dipertimbangkan dalam pembelian sayuran. Namun, variabel pemahaman gizi dan jumlah anggota keluarga berhubungan signifikan.

4. Dari empat pertimbangan keputusan pembelian, hanya terdapat perbedaan yang signifikan pada pertimbangan mengenai jenis sayuran antara konsumen di perkotaan dan pedesaan.

\section{DAFTAR PUSTAKA}

Abdul dan Indrie. 2009. Prospek Usahatani Tanaman Sayuran di Kabupaten Brebes. Jurnal Pengkajian dan pengembangan Teknologi Pertanian Vol.12 No.2 Hal. 135-145.

Hatane, Anette dan Hellen. 2007. Perilaku dan Keputusan Pembelian Konsumen Restoran melalui Stimulus 50\% Discount di Surabaya. Jurnal Manajemen Pemasaran Vol. 2 No. 2 Hal 73-80.

Kotler. 1998. Marketing Manajemen. Edisi 9. Prentice Hall International, Inc. New Jersey

Kotler dan Amstrong. 2001. Dasar-Dasar Manajemen. Gramedia Pustaka Utama. Jakarta.

Kuncoro, Mudrajad. 2003. Metode Riset Untuk Bisnis dan Ekonomi. Erlangga. Jakarta.

Maria dan Melly. 2007. Hubungan Pola Asuh Makan, Pengetahuan Gizi, Persepsi, Dengan Kebiasaan Makan Sayuran Ibu Rumah Tangga di Perkotaan dan Pedesaan Bogor. Jurnal Media Gizi dan Keluarga, Hal. 30-41.

Schiffman, Leon, G dan Leslie Lazar Kanuk. 2000. Consumer Behaviour. 7th ed. Prentice Hall. New Jersey.

Simamora, B. 2003. Membongkar Kotak Hitam Konsumen. Gramedia Pustaka Utama. Jakarta 